\title{
ANALISIS PENGGUNAAN TIPOGRAFI SPASIAL SANS SERIF DALAM RUANG PUBLIK TAMAN TEMATIK KOTA BANDUNG
}

\author{
Gema Arifrahara \\ Universitas Telkom, Fakultas Industri Kreatif, Desain Komunikasi Visual \\ gemariff@telkomunivesity.ac.id
}

\begin{abstract}
Abstrak
Penggunaan tipografi spasial tiga dimensi sebagai media informasi sudah lazim adanya, bahkan di kota Bandung pada setiap taman saat ini menggunakan pendekatan kreatif environmental tipografi. Ruang publik taman kota selain berperan sebagai paru-paru kota juga berperan sebagai ruang interaksi masyarakat, sangat baik untuk psikologis masyarakat dan memberikan sensasi modern. Taman kota yang ada di kota Bandung hampir sering dijumpai menggunakan pendekatan tipografi spasial Sans Serif seperti pada; Taman Tegal Lega, Taman Lansia, Taman Fotography, Taman Petpark, Taman Superhero, dan Taman lainnya. Objek tipografi sans serif tiga dimensi diamati secara deskriptif terhadap karakteristik huruf secara keterbacaan, legibility, keterlihatan dan kejelasannya dengan metode pencarian data melalui observasi objek tipografi pada display nama identitas taman. Permanfaatan tipografi sans serif pada ruang publik kota hanya bersifat fungsional sebagai penguat identitas semata tidak ditujukan sebagai penguat karakter kultural maupun simbolis.
\end{abstract}

Kata kunci: ruang publik, sans serif, taman kota Bandung, tipografi spasial

\begin{abstract}
The use of three-dimensional spatial typography as a medium of information was commonly used, even in the city of Bandung in every park using a creative approach to environmental typography. Apart from its role as city lungs, public space city parks also became a space for the community to interact, psychological healing in the city community, and providing a modern sensation. City parks in Bandung are often using the spatial typographic approach of Sans Serif as; Tegal Lega Park, Senior Park, Photography Park, Petpark Park, Superhero Park, and other Parks. Three-dimensional sans serif typographical objects are observed descriptively to the characteristics of letters in readability, legibilities, visibility, and clarity with data search methods through the observation of typography objects on the display of park identity names. The utilization of Sans Serif typographic in public spaces is only functional as an identity and it's not intended as a cultural or symbolic character booster.
\end{abstract}

Keywords: Bandung city park, public space, sans serif, spatial typography 


\section{PENDAHULUAN}

Desain tipografi pada saat ini banyak dimanfaatkan sebagai media display dengan menambah ukuran dimensi huruf yang diperbesar dan bersifat tiga dimensi. Tren semacam ini dijadikan pendekatan kreatif agar memberi perhatian pada suatu lokasi kepada masyarakat. Pada penelitian ini lebih menelaah pemanfaatan tipografi sans serif dalam ruang publik yang merupakan tempat di satukannya kekuatan budaya lokal dengan perkembangan peradaban modernisme saat ini. Ruang terbuka hijau berupa taman-taman terbuka direvitalisasi menjadi sebuah landscape yang ramah terhadap aktivitas fisik masyarakat dan menjadi tempat yang nyaman untuk berkumpul. Ruang terbuka merupakan tempat utama yang menjadi pusat dari perencanaan, ekonomi, politik, geografi dan sosiologi dari suatu masyarakat (Khawaja, 2015).

Elemen tipografi digunakan dalam sebuah ruang terbuka seperti taman kota sebagai unsur utama yakni sebagai media identitas berupa display nama sebuah tempat. Ruang hijau kota merupakan kebutuhan dari masyarakat urban untuk mengurangi tekanan psikologi sosial (Sagala et all, 2017). Selain fungsinya sebagai identitas bahwa tempat tersebut merupakan taman terbuka juga sebagai penarik perhatian masyarakat sehingga ada dorongan untuk mengunjungi tempat itu. Tipografi juga dapat digunakan sebagai monumen yakni benda yang menjadi pengingat atau tanda pada ruang terbuka (Puentes-Rivera, 2018).

Masyarakat Bandung sudah menjadi kelompok urban yang sebagian besar penduduknya merupakan penduduk campuran. Penduduk aslinya sudah mulai berkurang, terjadinya pernikahan antar suku daerah berbeda menambah tingkat heterogensi ditengah masyarakat. Perkembangan Kota Bandung saat ini semakin padat dan jumlahnya semakin tahun semakin meningkat, hal ini menambah beban kota dan pemerintah kota Bandung. Adanya taman-taman kota bertujuan untuk mengurangi tingkat stress masyarakat sekaligus meningkatkan angka indek kebahagiaan masyarakat kota.

Saat ini di beberapa kota besar di Indonesia marak akan fenomena pemanfaatan environmental tipografi sebagai salah satu media kreasi atau elemen dekoratif pada sebuah ruang publik. Tipografi environment merupakan salah satu bagian dari EGD (Environmental Graphic Design) yang lebih mengutamakan unsur tipografi sebagai unsur pembentuknya. Tipografi yang digunakan bersifat tiga dimensi dengan ukuran yang besar dan dengan warna yang mencolok agar terlihat kontras dengan latar ruang yang ada dibelakangnya.

Pemanfaatan tipografi dalam ruang terbuka dengan menggunakan pendekatan EGD akan menimbulkan beberapa permasalahan yang berkaitan dengan fungsi tipografi itu sendiri. Fungsi keterbacaan merupakan fungsi dasar dari teks agar dapat dipahami sebagai pesan oleh pembaca. Selain itu susunan teks dengan menggunakan jenis dan berat huruf, family huruf dan karakter huruf harus berkaitan dengan tema taman yang disampaikan. Masalah-masalah teknis lain yang berkaitan dengan tipografi seperti; kerning, tracking, leading dan spacing yang berkaitan dengan susunan huruf yang diterapkan. 
Tujuan dari penelitian ini adalah untuk menganalisis penerapan tipografi berkaitan dengan pendekatan tipografi sebagai elemen visual pada ruang publik khususnya taman kota sebagai elemen grafis lingkungan $(E G D)$ kaitannya dengan perkembangan psikososial masyarakat kota Bandung saat ini. Penelitian lebih difokuskan pada pemanfaatan dan penerapan tipografi huruf serta kaitannya ruang publik yang dijadikan tempat berinteraksi masyarakat khususnya taman-taman kota di Bandung. Tujuan ini adalah untuk dapat menemukan manfaat pada penerapan tipografi pada ruang publik melalui pendekatan tipografi environment terutama terhadap psikososial masyarakat.

Tipografi pada ruang publik memiliki relasi dengan gaya hidup masyarakat urban, yakni sebagai alat ekspresi individu maupun komunal sebagai bagian yang universal. Dalam riset tersebut fungsi tipografi lebih dikaitkan dengan pendekatan emosional masyarakat terutama dari gaya hidup terutama pada ruang publik (Nursaiman, 2012). Penelitian lain tentang tipografi dan ruang publik juga dibahas dalam penelitian Aulia yang menggunakan pendekatan tipografi pada ruang publik khususnya pada interior ruang harus melalui beberapa standar teknis yang mesti dipertimbangkan dalam perancangannya. Penelitian ini lebih menekankan pada interior ruang publik yang secara spesifik hanya memfokuskan pada ruang interior dalam gedung (Ruki \& Nediari, 2014).

Riset yang memiliki relasi kajian dengan yang diteliti oleh penulis namun berbeda topik kajian dan objek risetnya adalah penelitian tentang tipografi tiga dimensi pada kawasan wisata di Yogyakarta. Pada dasarnya banyak tipografi yang diterapkan pada ruang publik sebagai identitas sekaligus branding namun kurang menyentuh dari segi psikologis sosial terutama pendekatan tipografi dengan nilai kedalaman suatu kawasan (Noordyanto, 2019). Pada penelitian ini unsur branding tidaklah menjadi kajian utama namun tetap menjadi salah satu unsur yang dapat mempengaruhi persepsi pada ruang publik. Pada penelitian lain juga dibahas berkaitan dengan pemanfaatan ruang publik sebagai wadah berkumpulnya komunitas dan hanya melihat taman tematik di Kota Bandung sebagai pusat kumpul dari masyarakat yang memiliki komunitas atau hobi tertentu (Ilmiajayanti, 2015).

Masyarakat merupakan kelompok yang yang diuntungkan pada pembangunan ruang publik taman kota tematik di Kota Bandung. Masyarakat membutuhkan hiburan dan tempat bermain yang digunakan sebagai sarana interaksi sosial yang paling efektif (Puspitasari, 2018). Secara psikososial pembangunan taman-taman kota memberikan aspek positif di masyarakat terutama kelompok urban. Pemanfaatan tipografi spasial tiga dimensi adalah sebagai elemen visual penguat identitas baru suatu tempat. Visualisasi tipografi sans serif spasial tiga dimensi sebagai huruf display utama dalam ruang publik taman tematik kota Bandung untuk memenuhi fungsi keterbacaan, keterlihatan serta kemudahan dalam mengenalinya sebagai tulisan. 


\section{METODE PENELITIAN}

Analisa dalam penelitian ini menyoroti objek tipografi spasial melalui observasi mendalam melalui pendekatan dasar-dasar tipografi. Pendekatan tipografi yang dimaksud adalah melalui prinsip dasar; readibility (kemudahan dalam keterbacaan), legibility (kemudahan mengenali huruf), dan visibility (kemudahan keterbacaan dalam jarak tertentu) menurut Rustan dalam Isnandar \& Wantoro (2016).

Penelitian ini menggunakan metoda survei secara kualitatif melalui pendekatan deskriptif terhadap data primer maupun sekunder untuk mendukung proses analisa. Metode pencarian dan pengumpulan data melalui proses literatural, pengamatan dan observasi terhadap karakter objek serta wawancara baik secara khusus maupun secara umum melalui wawancara khusus secara proporsif kepada masyarakat yang mengetahui dan pernah memiliki pengalaman terhadap objek fokus kajian.

\section{HASIL DAN PEMBAHASAN}

\subsection{Tipografi Spasial 3D sebagai Tipografi Environment}

Tipografi merupakan kumpulan tanda yang bertujuan untuk memudahkan manusia dalam menyampaikan pesan dan menerimanya meski terpisah ruang dan waktu artinya tipografi merupakan salah satu bagian penting dari komunikasi (Fakhruddin et al., 2019). Tipografi Namun terdapat dua persepsi yang kuat dari tipografi yakni konteks dan konten bagaimana teks tersebut dibentuk dan dipresentasikan (Romano, 2012). Tipografi merupakan bagian dari sebuah esensi tulisan yang memiliki makna yang terdapat pada setiap term yang ada didalamnya. Term berisi maksud yang terdapat pada rangkaian huruf tertentu diluar dari proses sintaksisnya. Term tersebut berisi maksud yang dipahami oleh pembacanya. Namun tipografi juga melihat sisi representasi dari huruf yang ditampilkan sehingga memiliki karakter dan sifat yang dipersepsi pembacanya sebagai wujud emotif yang menguatkan term kata yang terbentuk.

Tipografi diteorikan sebagai unsur yang bersifat relatif, berdasarkan teori tentang seluruh pendekatan desain memanfaatkan tipografi sebagai elemen penting didalamnya. Hal tersebut ditegaskan oleh Ina Saltz dalam (Saltz, 2013). Hal tersebut dianalogikan sebagai hidangan yang memiliki rasa berbeda karena bahan-bahan yang disiapkan sesuai dengan selera dan jenis makanan yang disiapkan.

Tipografi Spasial tiga dimensi saat ini banyak digunakan sebagai identitas suatu tempat atau menjadi ciri atau tanda yang berdiri secara monumental. Pada umumnya tipografi spasial dikenal dengan istilah Large Lettering Design artinya menjadikan huruf menjadi tampilan unik berskala besar sehingga menarik perhatian orang yang melihat. Media ini pada umumnya digunakan sebagai petanda dari suatu momen berfungsi sebagai identitas yang juga memiliki makna dan arti konotasi maupun denotasi. Font merupakan istilah huruf telah mengalami perkembangan yang panjang dari nama sebuah satu set metal type sampai nama dari jenis font digital, yang saat ini sering digunakan seperti; Arial.ttf, Helvetica.ttf, Times New Romans.ttf atau Colibri.ttf (Wantoro \& Kasmana, 2017). 




Gambar 1. Large Lettering [Sumber: White Clouds 2019]

Perkembangan huruf tiga dimensi yang marak saat ini telah dimulai di negara-negara maju. Pendekatan tipografi melalui large letter seiring dengan perkembangan teknologi saat ini. Perkembangan tipografi tidak terlepas dari sejarah perkembangan dunia. Dimulai dari teknologi mesin cetak Guternberg berkembang sampai pada era digital saat ini. Jumlah huruf yang awalnya hanya terbatas kini jumlahnya menjadi ratusan ribu jenis huruf sehingga terus tumbuh dan bertambah.

Selain perkembangan digital mesin cetak dua dimensi berkembang juga mesin cetak tiga dimensi. Hal tersebut merevolusi beberapa perkembangan akan desain industri dan manufacturing. Pembuatan desain khususnya tiga dimensi tidak lagi membutuhkan waktu lama, karena kemampuan mesin $3 d$ print semakin maju dan semakin sempurna. Seluruh bahan, warna dan jenis material untuk membuat sebuah prototype dapat dengan sempurna dibuat sebelum proses produksi dilakukan (White Clouds, 2019).

Tipografi tiga dimensi dengan wujud huruf berskala besar sudah berkembang sejak lama di beberapa kota besar di dunia dan menjadi suatu simbol entitas dan branding dari suatu tempat atau lokasi. Banyak ikon lettering yang sangat dikenal dan banyak menginspirasi sehingga dituruti dibeberapa kota besar dunia lainnya.

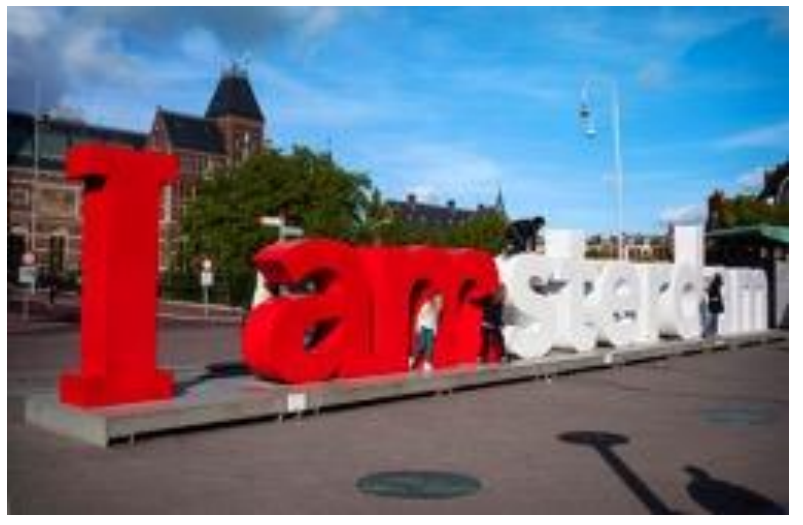

Gambar 2. City branding I Amsterdam

[sumber : Goerge Djadjarov, 2014, dalam fineartamerica, 2020] 
Pemanfaatan material dengan teknologi dan beberapa efek yang memberikan kesan lebih atraktif juga digunakan oleh beberapa lettering. Fungsi penempatan tipografi 3D dengan skala besar juga dimanfaatkan sebagai bentuk rekreasi bagi pengunjungnya, selain adanya budaya selfie sebagai bentuk eksistensi pada sosial media.

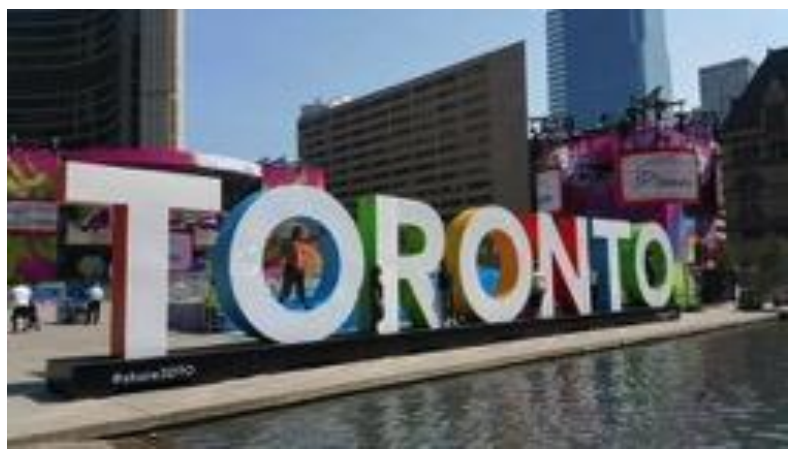

Gambar 3. Toronto City Branding

[Sumber: White Clouds 2019]

Fungsi dari tipografi spasial 3D, yang ditampilkan tegak merupakan bagian instalasi elemen hias pada ruang publik yang bertujuan sebagai penguat branding identitas tempat juga menjadi pusat perhatian masyarakat. Selain itiu juga sebagai tanda untuk menandakan suatu ruang yang juga digunakan sebagai medium selfie bagi netizen sebagai penghias ruang media sosial. Sebagai objek rekreasi untuk beberapa orang karena strukturnya dibangun ramah serta aman untuk anak-anak dan keluarga.

\subsection{Identitas Ruang Publik dalam Tipografi Spasial}

Ruang publik merupakan ruang dimana manusia berkumpul untuk merayakan perbedaan. Dibanyak kota ruang publik merupakan tempat bagaimana kota tersebut memberikan pelayanan kepada penduduknya baik masyarakat asli atau pendatang untuk menikmati dan menjadikan ruang selebrasi (Thrift, 2019).

Aksesibilitas ruang publik merupakan bagian penting, sejak pintu masuk (welcoming) kemudahan bagi seluruh masyarakat termasuk fasilitas kemudahan bagi penyandang disabilitas. Kenyamanan, keamanan, dan fasilitas merupakan syarat penting dari ruang publik. Ruang publik merupakan tempat masyarakat berekspresi, berinteraksi, duduk, bersantai, bercengkrama, bersama atau individu secara bebas. Fasilitas yang tersedia seperti kursi-kursi, tempat bermain anak, lapangan hijau dan ornamen patung yang interaktif juga menjadi media pelengkap ruang publik (Jaganath, 2018).

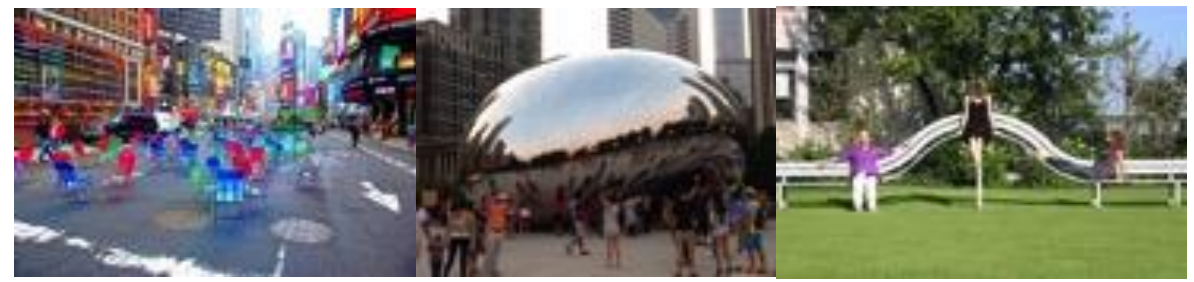

Gambar 4. Sarana dalam ruang publik

[Sumber: Jaganath, 2018] 
Identitas ruang publik umumnya diletakkan pada bagian gerbang utama pintu masuk suatu kawasan atau diletakan pada zona terbuka yang menjadi emphasis dari sebuah ruang publik. Identitas ini mengambil nama dari wilayah atau berdasarkan kesepakatan dari masyarakat serta pemerintah sebagai pemiliknya. Suatu kawasan ruang publik umumnya dinamai karena unsur kronologis kesejarahan atau berdasar suatu peruntukan.

Kota Bandung memiliki ruang publik yang berfungsi sebagai paru-paru kota juga sebagai tempat rekreasi warga kota baik berolahraga atau sekedar jalan-jalan menikmati taman kota. Taman kota di Bandung dinamai sesuai tema yang ditentukan oleh pemerintah dan masyarakat. Terdapat belasan taman di kota Bandung; seperti taman Lansia, taman Music, taman Fotografi, taman Superhero, taman Alun-alun Bandung, taman Dago, taman Pasopati, taman Cibeunying, taman Vanda, taman Radio dan taman lainnya.

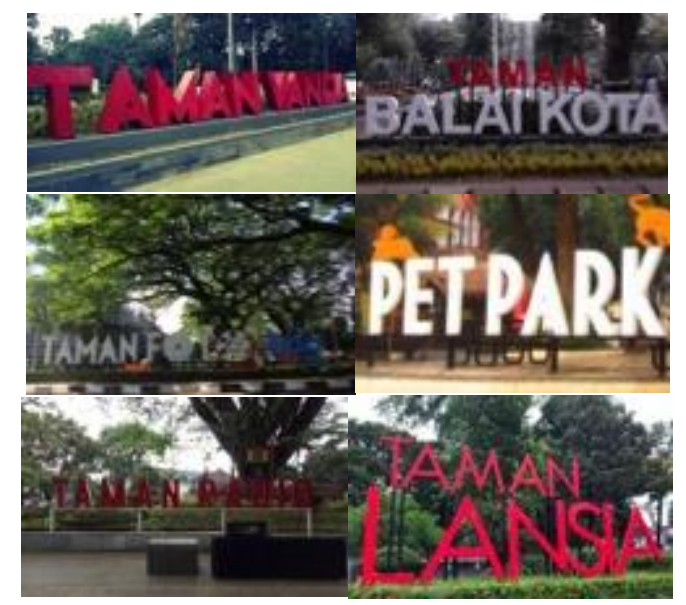

Gambar 5. Tipografi Spasial Sans Serif pada Taman Tematik Kota Bandung [Sumber: Pemprov JABAR 2017]

\subsection{Tipografi Spasial Sans Serif}

Tipografi Spasial dalam ruang publik taman tematik Bandung sangat menarik dengan nuansa warna merah dengan jenis huruf yang ditempatkan sebagai nama taman serta jenis huruf (typeface) yang berbeda-beda. Tipografi spasial merupakan bentuk kreasi yang saat ini banyak digemari dan dipelajari sebagai bentuk studi dari eksperimental tipografi (de León et al., 2019). Tipografi ruang dapat dipelajari berdasarkan pengenalan terhadap objek arsitektur yang dapat diterapkan secara eksperimental pada environmental tipografi (Kilic, 2012).

Tipografi memiliki beberapa macam jenis berdasarkan karakteristik bentuknya. Terdapat beberapa identifikasi huruf diantaranya; Jenis Serif atau berkait, non serif (sanserif) yang tidak berkait (Palm, 2018). Jenis lainnya menggunakan jenis huruf (script) tulisan tangan. Jenis dekoratif digunakan untuk menggambarkan karakter visual sesuai tema taman. 


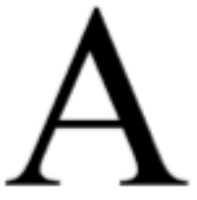

(a) Serif Berkait,

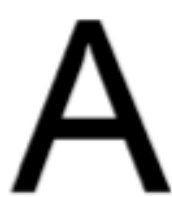

(b) Sans Serif, Tidak berkait

Gambar 6. Visualisasi Jenis Font

[Sumber : Palm, 2018]

Dari karakter jenis display huruf yang digunakan sebagian besar banyak berjenis sans serif atau tidak berkait dan sebagai kecil menggunakan jenis skrip. Tipe huruf Sans serif yang digunakan karakter allcaps seluruhnya huruf besar. Tujuan umum menggunakan huruf display tersebut agar lebih berkarakter tegas dan kuat serta berkesan modern.

Secara umum huruf terklasifikasi menjadi beberapa jenis huruf berdasarkan bentuk dan karakternya. Berdasarkan Alexander Lawson dalam (Rustan, 2011) dapat diklasifikasikan berdasarkan histori dan bentuk hurufnya.

Tabel 1. Analisisi huruf (typeface) berdasarkan klasifikasi huruf

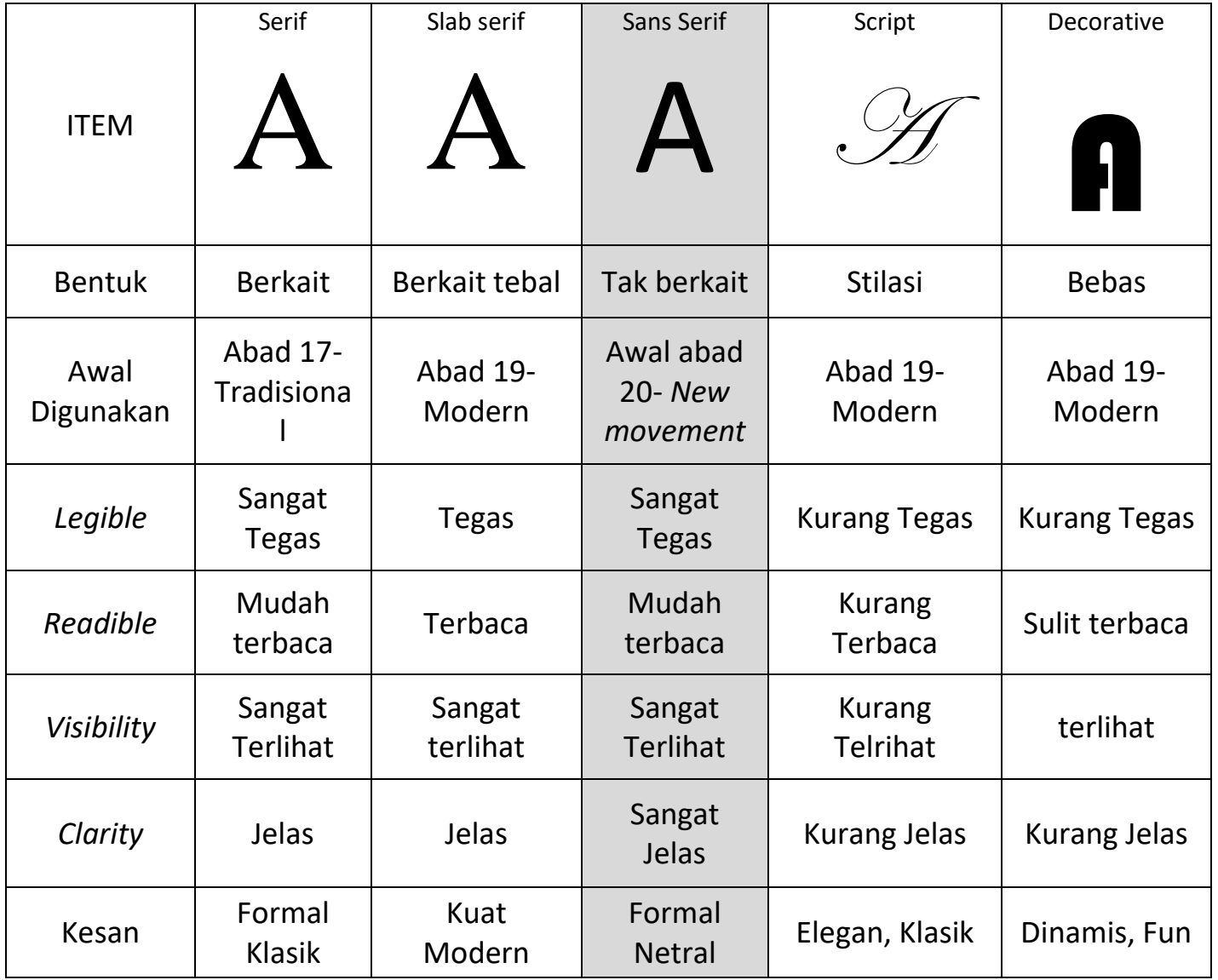

Berdasarkan tabel 1 menunjukkan karakter sans serif lebih memiliki fungsi sebagai jenis tipe huruf yang dapat digunakan pada banyak penerapan karena kesannya yang netral dan formal namun secara fungsional huruf dapat mewakili dari objek yang 
diidentitaskan. Tipe huruf sans serif juga digunakan karena mampu beradaptasi pada era modern saat ini sehingga mewakili dinamisasi perubahan pengelolaan ruang publik kota.

Pada Bentuk huruf dikenal juga berat huruf berat huruf yang digunakan umumnya berjenis black, bold, dan ada light. Pada display tipografi spasial taman tematik Bandung banyak menggunakan jenis family huruf dengan berat huruf berjenis Black atau Bold dan juga light atau regular. Hal tersebut bertujuan untuk memberikan karakter atau penegasan pada lokasi objeknya. Penggunaan jenis huruf sans serif yang berdasar standar jenis huruf aslinya tanpa ada sentuhan kreatif melalui pendekatan lokal kultural maupun karakter khusus dari tempat tersebut dikarenakan masih belum banyak tergalinya karakter visual kultural melalui pendekatan tipografi pada huruf jenis romans.

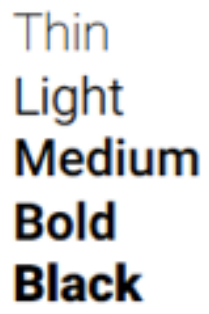

Gambar 7. Keluarga Huruf melalui perbedaan berdasarkan berat huruf

[Sumber : Palm, 2018]

Dasar dari penetapan ukuran huruf adalah panjangnya baseline tempat huruf ditempatkan. Dari display huruf yang ditampilkan nampak belum terdapat pendekatan kreasi tipografi pada ruang publik. Tampilan yang didisplay lebih memperlihatkan pendekatan formal yang menjauhkan dari bentuk eksperimental terhadap tipografi. Keterbatasan ini dikarenakan adanya batasan dari pihak regulator terhadap pelaksana dalam hal ini desainer tipografi environmental atau kemungkinan juga kemampuan aplikasi yang masih terbatas pada alat dan material.

Pendekatan warna umumnya memberikan sensasi atensi sehingga lebih banyak menggunakan warna merah dan putih. Pada aspek kekontrasan akan berdampak baik namun dari sisi sensasi kreasi nampak masih terpaku pada aturan formal. Pada dasarnya ada kemungkinan untuk menggunakan warna secara eksperimental namun masih belum tergalinya karakter ekspresif ruang publik, Hal ini dikarenakan kemunculan taman-taman tematik kota sebagai medium ruang publik yang masih relatif baru. Pemanfaatan warna hanyalah sebagai tanda serta identitas sebagai penguat perhatian agar dapat dengan mudah untuk dapat dikenali.

\subsection{Studi Signage Exterior Tipografi Sans Serif Spasial Tiga Dimensi}

Secara umum tipografi spasial yang terdapat pada ruang publik sebagai sistem komunikasi lingkungan (environment communication) yang bertujuan mempermudah pengguna dalam mencapai suatu tujuan (Zhang, 2017). Hal tersebut berhubungan dengan konsep penataan kota secara menyeluruh oleh pemerintah kota Bandung. Selain itu penempatan signage spasial juga berfungsi juga sebagai consumer brand 
engagement ( $\mathrm{CBE}$ ) yakni sebagai penguat kognisi, emosi dan perilaku terhadap kota Bandung dari warga kota (de Villiers, 2015). Pengaplikasian tipografi spasial pada area eksterior pada display taman tematik kota Bandung merupakan salah satu placemaking tipografi terhadap suatu kawasan atau dikatagorikan sebagai tipografi kawasan (Noordyanto, 2017).

Melihat perbedaan karakter tipografi dari masing-masing display huruf dan karakter tipografi spasial menunjukkan adanya ketidakseragaman konsep dan aplikasi pada sistem signage tipografi yang ada di kota Bandung. Karakter huruf tiga dimensi memiliki beberapa perspektif yang berbeda bergantung dari sudut pandang audien saat melihat. Hal tersebut yang unik yang dimiliki oleh huruf display tiga dimensi yang berbeda dengan huruf dua dimensi (Kim \& Choi, 2016).

Tabel 2. Karakteristik Tipografi Sans Serif Taman Tematik Kota Bandung [Sumber: Dokumentasi penulis]

\begin{tabular}{|c|c|c|c|c|c|c|c|}
\hline No & $\begin{array}{c}\text { Tipografi Sans Serif Spasial } \\
\text { Tema Taman }\end{array}$ & $\begin{array}{l}\text { Layout } \\
\text { Huruf }\end{array}$ & Family Huruf & Readibility & Legibility & Visibility & $\begin{array}{l}\text { Sifat } \\
\text { Huruf }\end{array}$ \\
\hline 1 & 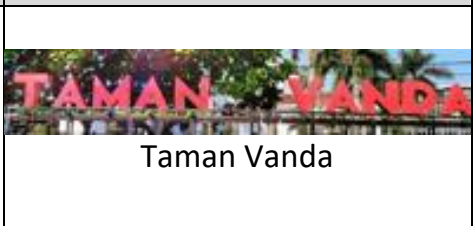 & $\begin{array}{l}\text { Antar huruf : } \\
\text { Renggang } \\
\text { Antar Kata : } \\
\text { Sangat } \\
\text { Renggang }\end{array}$ & $\begin{array}{l}\text {-Black } \\
\text {-Regular }\end{array}$ & terbaca & $\begin{array}{l}\text { Sangat } \\
\text { Dapat } \\
\text { dipahami }\end{array}$ & $\begin{array}{l}\text { Cukup } \\
\text { Terlihat }\end{array}$ & $\begin{array}{l}\text { Statis } \\
\text { Tegas } \\
\text { Formal }\end{array}$ \\
\hline 2 & Taman L & $\begin{array}{l}\text { Antar huruf: } \\
\text { Rapat } \\
\text { Antar Kata : } \\
\text { Rapat }\end{array}$ & $\begin{array}{l}\text {-Light } \\
\text { Extended } \\
\text {-Ringan }\end{array}$ & $\begin{array}{l}\text { Cukup } \\
\text { terbaca }\end{array}$ & $\begin{array}{l}\text { Cukup } \\
\text { dapat } \\
\text { dipahami }\end{array}$ & $\begin{array}{l}\text { Kurang } \\
\text { Terlihat }\end{array}$ & $\begin{array}{l}\text { Simple } \\
\text { Modern } \\
\text { Mature }\end{array}$ \\
\hline 3 & & $\begin{array}{l}\text { Antar huruf : } \\
\text { Rapat } \\
\text { Antar Kata : } \\
\text { Sangat } \\
\text { Renggang }\end{array}$ & $\begin{array}{l}\text {-Bold } \\
\text {-Condence } \\
\text {-Regular }\end{array}$ & terbaca & $\begin{array}{l}\text { Dapat } \\
\text { Dipahami }\end{array}$ & Terlihat & $\begin{array}{l}\text { Dinamis } \\
\text { Bermain }\end{array}$ \\
\hline 4 & & $\begin{array}{l}\text { Antar huruf : } \\
\text { Renggang } \\
\text { Antar Kata : } \\
\text { Rapat }\end{array}$ & $\begin{array}{l}\text {-Black } \\
\text {-Condence }\end{array}$ & $\begin{array}{l}\text { Jelas } \\
\text { terbaca }\end{array}$ & $\begin{array}{l}\text { Kurang } \\
\text { Dapat } \\
\text { Dipahami }\end{array}$ & Terlihat & $\begin{array}{l}\text { Fun } \\
\text { Dinamis }\end{array}$ \\
\hline 5 & Balai Kota Bandung & $\begin{array}{l}\text { Antar huruf: } \\
\text { Regular } \\
\text { Antar Kata : } \\
\text { Rapat }\end{array}$ & $\begin{array}{l}\text {-Black } \\
\text {-Regular } \\
\text {-Padat }\end{array}$ & $\begin{array}{l}\text { Jelas } \\
\text { terbaca }\end{array}$ & $\begin{array}{l}\text { Sangat } \\
\text { Dapat } \\
\text { Dipahami }\end{array}$ & $\begin{array}{l}\text { Kurang } \\
\text { Terlihat }\end{array}$ & $\begin{array}{l}\text { Statis } \\
\text { Formal }\end{array}$ \\
\hline 6 & Taman Radio & $\begin{array}{l}\text { Antar huruf : } \\
\text { Renggang } \\
\text { Antar Kata : } \\
\text { Renggang }\end{array}$ & $\begin{array}{l}\text {-Bold } \\
\text {-Condence }\end{array}$ & $\begin{array}{l}\text { Jelas } \\
\text { terbaca }\end{array}$ & $\begin{array}{l}\text { Sangat } \\
\text { Dapat } \\
\text { dipahami }\end{array}$ & $\begin{array}{l}\text { Sangat } \\
\text { Terlihat }\end{array}$ & $\begin{array}{l}\text { Statis } \\
\text { Formal }\end{array}$ \\
\hline
\end{tabular}


Berdasarkan tabel 2 diatas maka dapat disimpulkan berkaitan fungsi huruf sans serif pada tipografi spasial yang digunakan. Konstruksi keterbacaan, keterlihatan dan kemudahan dalam pemahaman menjadi fungsi utama yang menjadi momentum dari suatu tempat atau lokasi. Kemudahan terbaca dan kemudahan dalam mempersepsi maksud informasi pesan menjadi salah satu kekuatan fungsional yang dimiliki oleh karakter tipe huruf sans serif. Konsepsi karakter huruf yang membawa sifat dan arah pesan menjadi perhatian kedua dari penempatannya. Peran huruf sans serif spasial sebagai penguat identitas belum terolah secara maksimal dari sisi ide, konsep dan kreasinya. Artinya peran text display standing hanya berfungsi sebagai bentuk fisik statis formil yang lebih berperan sebagai bentuk baru dari sebuah pendekatan identitas display font yang umumnya terpasang secara tercetak dua dimensi atau tertanam pada sebuah dasar dinding.

Meskipun faktor budaya tidak menjadi perhatian utama namun sensasi budaya sebaiknya terlibat dalam penciptaan karya tipografi. Budaya, style dan aspek konotasi lainnya pada penerapan jenis huruf dan berkontribusi pada proses persepsi pengunjung baik lokal maupun pendatang terhadap tempat atau daerah tersebut (Fleischman, 2016). Pada Tipografi spasial pada taman tematik kota Bandung tidak menjadi suatu perhatian khusus sehingga yang digunakan merupakan budaya popular yang lebih bersifat modern.

\section{KESIMPULAN}

Tipografi spasial Sans Serif tiga dimensi yang digunakan dalam huruf display pada Taman Tematik Kota Bandung berfungsi sebagai pengokoh dan tetap berkarakter modern. Karakter yang diharapkan pada ruang publik Bandung adalah modern, simpel, dan tegas. Formalitas pada tampilan tipografi spasial taman tematik kota tetap dipertahankan sebagai pesan pemerintah kota kepada masyarakat kota. Kurangnya kreasi tipografi pada ekspresi pada ruang publik karena status formal yang tidak bisa lepas dari fungsi huruf sebagai identitas dan signage semata. Pemerintah kota Bandung melakukan pemugaran terhadap terhadap ruang hijau menjadi lebih bernuansa modern dan agar bisa berasimilasi dengan perkembangan sosial juga kemajuan teknologi saat ini.

Penggunaan huruf sans serif mendominasi dan monoton sehingga pengunjung tidak memberikan sensasi emosional kepada masyarakat. Aspek budaya tidak terlalu dilibatkan secara konotatif meskipun memberikan kontribusi yang sangat baik. Pemanfaatan karakter budaya lokal Sunda yang kaya akan unsur dekoratif serta beragam jenis warna sangat potensial untuk dapat disatukan dalam tipografi spasial, namun belum banyak tergali untuk dijadikan aspek penguat identitas kultural. Artinya penggunaan display tipografi sans serif saat ini pada suatu kawasan di kota Bandung adalah sebagai penguat formalitas pemerintah yang bertranformasi mengikuti perubahan sosial yang terjadi. 


\section{DAFTAR PUSTAKA}

de León, A. B., Saorin, J. L., de la Torre-Cantero, J., Meier, C., \& Cabrera-Pardo, M. (2019). Flexible 3D printed molds for educational use. Digital fabrication of 3D tipografi. International Journal of Online and Biomedical Engineering, 15(13), 4-16.

de Villiers, R. (2015). Consumer brand enmeshment: Tipografi and complexity modeling of consumer brand engagement and brand loyalty enactments. Journal of Business Research, 68(9), 1953-1963.

Fakhruddin, D., Sachari, A., \& Haswanto, N. (2019). Pengembangan Desain Informasi dan Pembelajaran Aksara Jawa melalui Media Website. ANDHARUPA: Jurnal Desain Komunikasi Visual \& Multimedia, 5(01), 1-23.

Fleischman, K. (2016). Lettering and Signage in the Urban Environment of North Queensland's Capital: Tropical Flair or Univernacular? ETropic: Electronic Journal of Studies in the Tropics, 10, 83-95.

Freska Ilmiajayanti, D. I. K. D. (2015). Persepsi Pengguna Taman Tematik Kota Bandung Terhadap Aksesibilitas dan Pemanfaatannya. 1(1), 21-30.

Isnandar, A. R., \& Wantoro, W. (2016). Analisis Tipografi pada Logotype Band Forgotten. ANDHARUPA: Jurnal Desain Komunikasi Visual \& Multimedia, 2(02), 121136.

Jaganath, Thejas. The Importance of Public Spaces. medium.com. https://medium.com/@thejas009/the-importance-of-public-spaces5bb49ba6c000. Project for Public Space. 2018.

Khawaja, H. (2015). Public Spaces under Threat : Scenes from Amman (Vol. 33, Issue 0) [ÉCOLE POLYTECHNIQUE DE L'UNIVERSITE FRANÇOIS RABELAIS DE TOURS]. www.polytech-univ-tours.fr

Kilic, E. (2012). 2D Environmental/Spatial Tipografi Practice for Graphic Design Students. Procedia - Social and Behavioral Sciences, 46, 3063-3067.

Kim, S., \& Choi, S. (2016). Automatic generation of 3D tipografi. SIGGRAPH 2016 - ACM SIGGRAPH 2016 Posters, 1-2.

Naufan Noordyanto. (2019). Fungsi Tanda Identitas Area Berwujud Tipografi Tiga Dimensi Di Daerah Istimewa Yogyakarta Jurnal. JURNAL TUGAS AKHIR, 4(1), 75-84.

Noordyanto, N. (2017). Studi Tipografi Kawasan Di Yogyakarta. DeKaVe, 9(1), 65-84.

Nursaiman, D. (2012). Relasi Enviromental Tipografi, Public Space Dan Gaya Hidup. Visualita, 4(1), 42-57.

Palm, K. (2018). Design and use of 3D tipografi for indoor Augmented Reality mobile applications.

Puentes-Rivera, Y. (2018). WHISPERS OF MEMORY, MURMURS OF HISTORY ACOUSTIC MONU-MEMORIALS IN PUBLIC SPACES. Bauhaus-Universität Weimar.

Puspitasari1, C. (2018). Taman Sebagai Ruang Bermain Di Dalam Kota : Perancangan " Taman Maen ."

Ruki, U. A., \& Nediari, A. (2014). PENERAPAN TIPOGRAFI DALAM SISTEM SIGNAGE PADA INTERIOR RUANG PUBLIK. 5(9), 822-832.

Rustan, Surianto (2011). Font \& TIPOGRAFI. Ed 1, Gramedia Pustaka Utama, Jakarta 
Sagala, Anendawaty Roito and Prasetyo, Adityas and Syakur, Dwi Abdul and Amania, Nur Rahmah and Radnawati, Daisy and Syahadat, Ray March and Putra, P. T. (2017). Perencanaan Taman Kota sebagai Salah Satu Atribut Kota Hijau di Kecamatan Gedebage, Bandung. Vitruvian: Jurnal Arsitektur, Bangunan, \& Lingkungan, 6(3), 85-90.

Wantoro, W., \& Kasmana, K. (2017). Perancangan Font Tapych Berbasis Karakter Visual Motif Tapis Lampung. ANDHARUPA: Jurnal Desain Komunikasi Visual \& Multimedia, 3(01), 81-91.

White

Clouds.

(2019).

https://www.whiteclouds.com/largeletters/fineartamerica2020https://fineartamerica.com/featured/thefamous-giant-letters-of-amsterdam-georgi-djadjarov.html

Zhang, L. U. (2017). Wayfinding streetscapes. 